\title{
Evidence for the ambiguity of the term constipation: the role of irritable bowel syndrome
}

\author{
C S J Probert, P M Emmett, H A Cripps, K W Heaton
}

\begin{abstract}
A satisfactory definition of constipation is elusive. An important and measurable element is slow colonic transit. Whole gut transit time, a proxy for colonic transit time, can be estimated from self recorded data on stool form and frequency. Our aim was to compare whole gut transit time with subjective definitions in the context of the general population. In a community based sample of 731 women aged 25-69 years the estimated whole gut transit time was compared with two subjective assessments of constipation - the woman's own perception and a symptom based definition proposed by an international working team (Rome definition). We have defined slow whole gut transit time as $>2 \mathrm{SD}$ above the mean in women who seldom passed lumpy stools (that is, $>92$ hours). Slow transit was present in $9.3 \%$ of the sample. Similar numbers met the subjective definitions $(8 \cdot 5 \%$ and $8 \cdot 2 \%)$. However, the overlap between the three definitions was poor. Of 68 women with estimated slow transit, 28 had self perceived constipation, 20 had Rome defined constipation, and only 11 had both. Of subjects classified as constipated by the subjective definitions only $37 \%$ had slow transit; they had a high prevalence of irritable bowel symptoms. In conclusion, this study showed that the term constipation is ambiguous and often misleading and that attempts to base a definition on symptoms are misguided. In epidemiological studies, conclusions about the prevalence of constipation should be based on records of stool type and timing. (Gut 1994; 35: 1455-1458)
\end{abstract}

The definition of constipation is contentious. Some would say it is difficulty in the act of defecation but such difficulty is subjective and has many causes. For most gastroenterologists, the essence is infrequent defecation or the passage of small or hard stools. ${ }^{1}$ In this definition, all three adjectives imply slow colonic transit. Infrequency obviously does so, whereas smallness and hardness of the stools are closely associated with slow transit. ${ }^{2}$ Ideally, therefore, any assessment of constipation should include the measurement of colonic transit time or, as a proxy, whole gut transit time. This is impracticable in ordinary clinical practice so doctors are forced to depend on patients' accounts and these are fallible. People are inaccurate in recalling their bowel frequency, ${ }^{3}$ which is a poor guide to transit time anyway. ${ }^{45}$ Patients often equate straining at stool and feelings of incomplete evacuation with constipation but these symptoms occur in the irritable bowel syndrome. ${ }^{6}$

Despite these problems, doctors and research workers often accept patients' statements that they are constipated. ${ }^{7-9}$ An international working team felt obliged to include symptoms of straining and incomplete evacuation in its definition of constipation, called here the Rome definition. ${ }^{10}$ Earlier work ${ }^{6}{ }^{11} 12$ led us to suspect that these subjective approaches confuse objective, slow transit constipation with the fruitless straining that occurs in irritable bowel syndrome. They also overlook asymptomatic slow transit, which could be important because slow transit and low faecal output have been linked with bowel cancer and gall stones. ${ }^{13} 14$

To find out if these suspicions are justified requires the study of a large sample of the population in which self perceived constipation and Rome defined constipation are compared with a measurement of colonic transit time or faecal output. We became able to do this when we discovered that, in women, whole gut transit time can be predicted from a self made recording of three defecations combined with systematic questioning about bowel habit. ${ }^{15}$

\section{Subjects and methods}

The 731 women in this study were a subsample of 1059 volunteers who attended for a survey concerned primarily with the prevalence and causes of gall stones. ${ }^{16}$ The original subjects were a stratified random sample of women aged 25-69 from east Bristol. The subsample of 731 consisted of the $69 \%$ of volunteers who managed to keep a record of three consecutive defecations as well as answering a questionnaire about their bowel habit. The record included, for each bowel action, date and time, and stool form or appearance on the Bristol stool form scale, which reflects transit time. ${ }^{4}$ From the data on the record form whole gut transit time was calculated from a formula derived by multiple regression analysis ${ }^{15}$ :

whole gut transit time $=103-1.23(\mathrm{DF})-4.69(\mathrm{SFS})+10.638(\mathrm{IDTI})$

where DF was defecation frequency per week, SFS was stool form score (the sum of three 


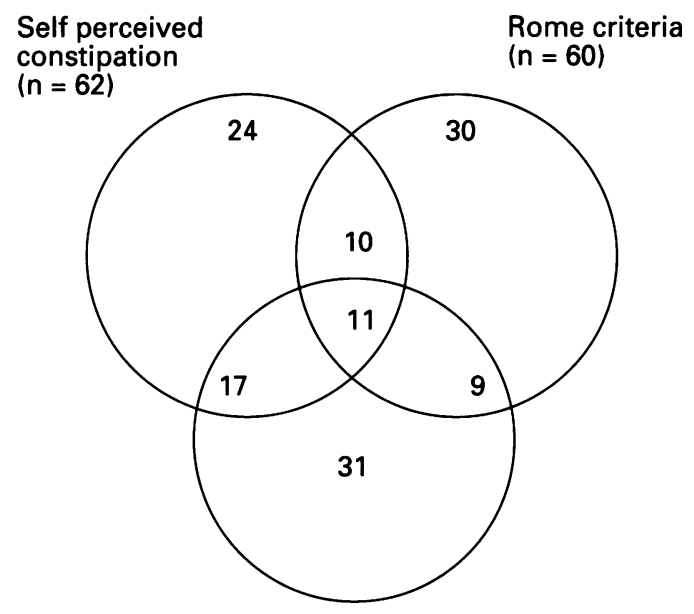

Slow transit (ETT>92 hours) $(\mathrm{n}=68)$

Venn diagram showing the overlap between the three groups. ETT=estimated transit time.

stool form numbers), and IDTI was mean interdefecatory time interval. Whole gut transit time estimated in this way correlates with measured transit time in women $(r=0.74$, $\mathrm{p}<0.001) .{ }^{15}$

An agreed basis for defining normal whole gut transit time does not exist. We decided to base it on the findings in our subjects $(n=517)$ who seldom passed lumpy stools (stool form score $\geqslant 9$ ). These women had a normal distribution of whole gut transit times (mean (SD) $=54$ (19) hours). Transit time $>2$ SD above the mean was defined as slow, that is, $>92$ hours.

In a subsample of 60 women whole gut transit time was actually measured ${ }^{15}$ using a modification of the radio-opaque marker technique. ${ }^{17}$

The Rome definition of constipation ${ }^{10}$ requires two or more of the following criteria to be reported (when not taking laxatives): (a) straining on $\geqslant 25 \%$ of bowel movements, (b) feeling of incomplete evacuation after $\geqslant 25 \%$ of bowel movements, (c) hard or pellety stools on $\geqslant 25 \%$ of bowel movements, (d) stools passed $<3 /$ week. The definition requires that the Rome criteria for diagnosing irritable bowel syndrome ${ }^{18}$ are not met.

Of the four criteria for constipation, (a) and (b) were identified by a questionnaire in which subjects were asked how often they strained or had feelings of incomplete evacuation and had to choose from: never, occasionally $(<25 \%$ of occasions), often ( $\geqslant 25 \%-50 \%$ of occasions), usually ( $\geqslant 50-<100 \%$ of occasions) or always. Criterion (c) was taken as an answer of type 1 or 2 to the question 'What is your usual or commonest stool type?', when the subject was

TABLE I Transit time of women with and without symptoms thought to reflect constipation

\begin{tabular}{llll}
\hline & \multicolumn{4}{l}{ Median estimated transit time in hours (interquartile range) } & \\
\cline { 2 - 4 } Symptom & With symptom & Without symptom & p Value \\
\hline Straining & $76.9(64$ to 90$)(n=101)$ & $59 \cdot 2(49$ to 73$)(n=630)$ & $<0.001$ \\
Incomplete evacuation & $66.3(53$ to 90$)(n=83)$ & $61.3(50$ to 75$)(n=648)$ & $<0.05$ \\
Stool type 1 or 2 & $78.9(63$ to 88$)(n=184)$ & $57 \cdot 4(47$ to 69$)(n=547)$ & $<0.001$ \\
Bowels open <3/week & $98.4(90$ to 129$)(n=19)$ & $61.0(50$ to 75$)(n=712)$ & $<0.001$ \\
\hline
\end{tabular}

shown a list of the first six types of the Bristol scale. ${ }^{4}$ Criterion (d) was obtained by asking 'How many times in the week do you usually open your bowels?'.

Symptoms of irritable bowel syndrome were identified from the same questionnaire, which incorporated the six Manning criteria ${ }^{19}$ plus questions on straining, urgency, and runny stools, the answer choices being as before.

Self perceived constipation was identified from the subjects' answer of often, usually or always to the question 'Do you consider yourself to be constipated?', this question being asked, in nearly all cases, immediately before the bowel recording. To calculate the number of these subjects who could be expected to have prolonged transit during the bowel recording we assumed that 'usually' meant $50-100 \%$ of occasions and 'often' meant $25-50 \%$. Thus, the expected number included all those who said always, $75 \%$ of those who said usually, and $37.5 \%$ of those who answered often.

Venn diagrams were used to show the extent of agreement between the three definitions - self perception, slow transit, and Rome definition.

The prevalence of irritable bowel symptoms $\mathrm{s}^{20}$ in subjects meeting each definition of constipation was calculated and expressed as the odds ratio (versus subjects who did not meet them).

Duplicate estimates of transit time were available in 47 women and were compared to assess whether intrasubject variation in transit time may have biased our results.

\section{Results}

The numbers of subjects defined as constipated by the three methods were similar: 68 by slow transit, 62 by self perception, and 60 by the Rome definition $(9 \%, 9 \%$, and $8 \%$ respectively). There was poor agreement, however, between the definitions (Figure). Of the women with slow transit, $41 \%$ perceived themselves as constipated and $29 \%$ met the Rome definition; $16 \%$ were identified by both subjective definitions. Conversely, of 101 women classed as constipated by one or both of the subjective definitions 37 had slow transit.

With each Rome criterion transit time was longer in those who fulfilled it than in those who did not (Table I). There was much overlap in interquartile ranges, however, with regard to straining and incomplete evacuation. Slow transit (>92 hours) was present in only $23 \%$ of 101 women who often strained and in only $24 \%$ of 83 who had incomplete evacuation. Subjects who met the Rome definition only because they had straining and incomplete evacuation $(n=18)$ had normal whole gut transit time (64 hours, SD $25 v 63$ hours, SD 22 in subjects without these symptoms). The Rome criteria also agreed poorly with self assessed constipation - with one exception; 13 of $24(54 \%)$ of women with infrequent defecation thought themselves constipated. The equivalent figure, however, 
TABLE II Odds ratio (95\% confidence intervals) of having symptoms of irritable bowel syndrome ${ }^{\star}$ in subjects identified as constipated by three definitions

\begin{tabular}{|c|c|c|c|}
\hline & Slow transit & Rome definition & Subjects' perception \\
\hline $\begin{array}{l}\text { One or more symptoms } \dagger \\
\text { Two or more symptoms } \\
\text { Three or more symptoms } \dagger \\
\text { Recurrent intestinal pain } \ddagger\end{array}$ & $\begin{array}{l}2.7(1.5 \text { to } 4.9) \\
1.8(0.9 \text { to } 3.4) \\
1.9(0.9 \text { to } 4.2) \\
1.1(0.5 \text { to } 2.2)\end{array}$ & $\begin{array}{l}13 \cdot 1(5 \cdot 1 \text { to } 33 \cdot 8) \\
2 \cdot 3(1 \cdot 2 \text { to } 4 \cdot 5) \\
1 \cdot 1(0 \cdot 4 \text { to } 2 \cdot 9) \\
\text { NA }\end{array}$ & $\begin{array}{l}5 \cdot 5(2 \cdot 7 \text { to } 11) \\
4 \cdot 1(2 \cdot 2 \text { to } 7 \cdot 7) \\
6 \cdot 9(3.5 \text { to } 13 \cdot 4) \\
3 \cdot 4(1.9 \text { to } 6 \cdot 1)\end{array}$ \\
\hline
\end{tabular}

*The six Manning criteria plus watery stools, urgency, and straining to finish, all or $\geqslant 1$ in 4 occasions. ${ }^{21}+$ In the $79 \%$ of constipated women who provided data on all symptoms $(n=51,43$ occasions. ${ }^{21}+$ In the $79 \%$ of constipated women who provided data on all symptoms $(n=51,43$ and 47 respectively) $v$ those who did not fulfil the definition of constipation ( $n=528,536$, and
532 respectively). $\neq n=60,68$, and 62 respectively, $v 663,671$, and 669 respectively. Recurrent defined as $>6$ times in the past year; intestinal pain defined as pain fulfilling any of the Manning criteria (relief with defecation on $\geqslant 1$ in 4 occasions, association with looser stools, association with more frequent stool). NA $=$ Not applicable.

for straining was $38 \%$, for incomplete evacuation $33 \%$, and for passing lumpy stools $19 \%$.

Overall, people with self assessed constipation had longer transit times than those without (median 89 hours $v 60$ hours). The number found to have prolonged whole gut transit time was less, however, than expected (28 v 43; $\left.\chi_{1}^{2}=5 \cdot 2, \mathrm{p}<0.05\right)$.

The likelihood of having irritable bowel symptoms was significantly increased in subjects who met the Rome definition of constipation and in those who perceived themselves as constipated (Table II). So, too, was the likelihood of having recurrent intestinal pain in women with self assessed constipation.

Among the women whose whole gut transit time was measured directly, $36(60 \%)$ also provided sufficient details to be classifiable by the Rome definition. Of these, four had prolonged transit; only one of them was recognised as constipated by either the Rome definition or self perception. Three of them thought they were constipated and three were by the Rome definition, but only one of either group had prolonged transit. Such small numbers preclude statistical evaluation but they agree with the earlier data.

Regarding intrasubject variability, no difference was found between the two estimates of transit time $(z=-0.9, p=0.92)$.

\section{Discussion}

A limitation of this study is that a single measurement of transit time was assumed to be representative for each subject. Intrasubject variation is well recorded, ${ }^{21}$ even on a constant diet, ${ }^{22}$ and could have resulted in some misclassification into normal and slow groups. Such variation is less, however, than intersubject variation, ${ }^{22} 23$ and was comparatively minor in this study.

We have compared a validated estimate of whole gut transit time with self perceived constipation and the Rome definition and found little agreement. Both these subjective definitions classified many people as constipated though their transit times were normal. The reason seems to be that the subjective definitions are biased by symptoms of irritable bowel syndrome. Many subjects satisfied the Rome definition simply because they had feelings of incomplete evacuation and strained (the one possibly causing the other $\left.{ }^{618}\right)$. The data call into question the validity of the Rome definition and any other definition based on symptoms except for infrequency of defecation.

The finding that many people who think they are constipated have normal intestinal transit has been made before, but only in the context of patients referred to specialist clinics, ${ }^{324}$ not in the context of the general population. We did not ask our subjects what made them think they were constipated but their perceived constipation was weakly related to two symptoms commonly presumed to be caused by constipation, namely straining and incomplete evacuation. Elderly people who think they are constipated tend to be psychologically distressed and to report more illnesses. ${ }^{25}$ Whether this applies to other age groups needs to be investigated.

Subjective criteria for constipation failed to detect almost half the women with slow transit. As slow transit is now believed to predispose to gall stones and bowel cancer, ${ }^{13} 14$ attempts to identify subjects at risk for these diseases should not rely on subjective criteria for constipation. We suggest that future epidemiological studies in this area should include prospective records of stool form as well as of stool frequency. We also recommend that physicians never take patients' complaints of constipation at face value but ask them to keep a record of several defecations. From this it will be clear whether the stools are lumpy or infrequent, either of which imply that transit is slow.

Supported by grants from South West Regional Health Authority and Kellogg Company of Great Britain. C Symes helped in the collection and presentation of data.

1 Sleisenger MH, Fordtran JS. Gastrointestinal disease: pathophysiology, diagnosis, treatment. 4th ed. Philadelphia: Shysiology, diagnders, 1989.

2 Davies GJ, Crowder M, Reid B, Dickerson JWT Bowel function measurements of individuals with different eating patterns. Gut $1986 ; 27: 164-9$.

3 Chaussade S, Khyari A, Roche H, Garret M, Gaudric M, Couturier D, et al. Determination of total and segmenta colonic transit time in constipated patients. Results in 91 patients with a new simplified method. Dig Dis Sci 1989; 34: 1168-72.

4 O'Donnell LJD, Virjee J, Heaton KW. Detection of pseudodiarrhoea by simple clinical assessment of intestinal transit rate. $B M \mathcal{F} 1990 ; 300: 439-40$.

5 Hutchinson $R$, Notghi A, Harding LK, Kumar $D$. Symptoms in the irritable bowel syndrome do not correlate with colonic transit abnormalities. Gut 1993; 34 (suppl 4): S4.

6 Heaton KW, Ghosh S, Braddon FEM. How bad are the symptoms and bowel dysfunction of patients with the irritable bowel syndrome? A prospective, controlled the irritable bowel syndrome? A prospective, controlled
study with emphasis on stool form. Gut 1991; 32: study

7 Everhart JE, Go VLW, Johannes RS, Fitzsimmons SC, Roth HP, White LR. A longitudinal survey of reported bowe habits in the United States. Dig Dis Sci 1989; 34 1153-62.

8 Sonnenberg A, Koch TR. Physician visits in the United States for constipation: 1958 to 1986. Dig Dis Sci 1989, 34: 606-11.

9 Sonnenberg A, Koch TR. Epidemiology of constipation in the United States. Dis Colon Rectum 1989; 32: 1-8.

10 Drossman DA, Thompson WG, Talley NJ, Funch-Jensen $P$, Janssens J, Whitehead WE. Identification of sub-groups of functional gastrointestinal disorders. Gastroenterology of functional gastrointestinal

11 Oettle GJ, Heaton KW. 'Rectal dissatisfaction' in the irritable bowel syndrome. A manometric and radiological table bowel syndrome. A manometric
study. Int $\mathcal{f}$ Colorect Dis $1986 ; 1: 183-5$.

12 Oettle GJ, Heaton KW. Is there a relationship between symptoms of the irritable bowel syndrome and objective measurements of large bowel function? A longitudinal study. Gut 1987; 28: 146-9.

13 Cummings JH, Bingham SA, Heaton KW, Eastwood MA Fecal weight, colon cancer risk and dietary intake of nonstarch polysaccharides (dietary fiber). Gastroenterology 1992; 103: 1783-9. 
14 Heaton KW, Emmett PM, Symes CL, Braddon FEM. An explanation for gallstones in normal-weight women: slow intestinal transit. Lancet 1993; 341: 8-10.

15 Probert CSJ, Emmett PM, Heaton KW. Intestinal transit time in the population calculated from self-made observations of defaecation. F Epidemiol Community Health 1993; 47: 331-3.

16 Heaton KW, Braddon FEM, Mountford RA, Hughes AO, Emmett PM. Symptomatic and silent gallstones in the community. Gut 1991; 32: 316-20.

17 Marcus SN, Heaton KW. Intestinal transit time, deoxycholic acid and the cholesterol saturation of bile - three inter-related factors. Gut 1986; 27: 550-8.

18 Thompson WG, Creed F, Drossman DA, Heaton KW Mazzacca G. Functional bowel disease and functional abdominal pain. Gastroenterology International 1992; 5:

19 Manning AP, Thompson WG, Heaton KW, Morris AF Towards positive diagnosis of irritable bowel syndrome. $B M \mathcal{F}$ 1978; 2: 653-4.
20 Heaton KW, O'Donnell LJ, Braddon FEM, Mountford RA, Hughes AO, Cripps PJ. Symptoms of irritable bowe syndrome in a British urban community: consulters and non-consulters. Gastroenterology 1992; 102: 1962-7.

21 Wyman JB, Heaton KW, Manning AP, Wicks ACB Variability of colonic function in healthy subjects. Gut 1978; 19: $146-50$

22 Cummings JH. Diet and transit through the gut. In: Heaton KW, ed Dietary fibre: current developments of importance to health. London: Libbey, 1978: 83-95.

23 Cummings JH, Jenkins DJA, Wiggins HS Measurement of the mean transit time of dietary residue through the human gut. Gut 1976; 17: 210-8.

24 Turnbull GK, Barton CI, Lennard-Jones JE. Radiological studies of rectal evacuation in adults with idiopathic constudies of rectal evacuation in adults with idiop

25 Whitehead WE, Drinkwater D, Cheskin L Heller BR Whitehead WE, Drinkwater D, Cheskin LJ, Heller BR, Schuster MM. Constipation in the elderly living at home.
Definition, prevalence and relationship to lifestyle and health status. $\mathcal{F}$ Am Geriatr Soc 1989; 37: 423-9. 